\title{
Pengaruh Sektor Transportasi dan Komunikasi terhadap PDRB di Kota Dki Jakarta
}

\author{
Violina Anastasya, Try Monica, Rina Rosadah, Eurico
}

Universitas Internasional Batam, Indonesia

Email: 1941265.violina@uib.edu, 1941337.try@uib.edu, 1941130.rina@uib.edu,

1941128.eurico@uib.edu

\begin{abstract}
Artikel info
Artikel history:

Diterima 07 Mei 2021

Diterima dalam bentuk revisi 13 Mei 2021

Diterima dalam bentuk revisi 19 Mei 2021
\end{abstract}

Keywords:

transportation,

communication, PDRB

Kata kunci:

transportasi, komunikasi, PDRB

\begin{abstract}
The purpose of this research is to find out what sectors have the most influence and become the biggest contributors. Transportation and communication is one of the factors that affect the income of a region or country. The type of research method that we process is in the form of qualitative data analysis, this method is a method that we collect to process and sort the data we have obtained so that it fits the topics discussed. This is because the development of transportation and communication media is very advanced, especially in the modern era. Transportation mobility and movement in DKI Jakarta can affect economic growth and regional income. This research was conducted to determine how much influence the transportation and communication sector has on regional income in DKI Jakarta by using the method of documentation and data collection taken from the DKI Jakarta statistical center. Important sectors in this research are transportation and communication. It can be concluded that the transportation sector has a significant effect on regional income in DKI Jakarta. Because the movement and mobility in this city is very high. In 2019 the transportation sector contributed $3.44 \%$. Based on these facts, the transportation sector has a significant effect on the Original Regional Income of DKI Jakarta.
\end{abstract}

\begin{abstract}
Abstrak
Tujuan Penelitian ini Untuk mengetahui sektor apa yang paling berpengaruh dan menjadi penyumbang terbesar. Transportasi dan komunikasi merupakan salah satu faktor yang mempengaruhi pendapatan suatu daerah atau negara. Jenis metode penelitian yang kami proses berupa analisis data kualitatif, metode ini merupakan metode yang kami kumpulkan untuk memproses dan mengurutkan data yang telah kami dapatkan supaya sesuai dengan topik yang dibahas. Hal ini dikarenakan perkembangan media transportasi dan komunikasi sangat maju terutama di era modern. Mobilitas transportasi dan pergerakan di DKI Jakarta dapat mempengaruhi pertumbuhan ekonomi dan pendapatan daerah. Penelitian ini dilakukan untuk mengetahui seberapa besar pengaruh sektor pengangkutan dan komunikasi terhadap pendapatan daerah DKI Jakarta dengan menggunakan metode dokumentasi dan pengumpulan data yang diambil dari pusat statistik DKI Jakarta. Sektor penting dalam penelitian ini adalah transportasi dan komunikasi. Dapat disimpulkan bahwa sektor transportasi berpengaruh signifikan terhadap pendapatan daerah DKI Jakarta. Karena pergerakan dan mobilitas di kota ini sangat tinggi. Pada 2019 sektor transportasi memberikan kontribusi 3,44\%. Berdasarkan fakta tersebut, sektor transportasi berpengaruh signifikan terhadap Pendapatan Asli Daerah DKI Jakarta.
\end{abstract}

Coresponden author: Violina Anastasya Email: 1941265.violina@uib.edu artikel dengan akses terbuka dibawah lisensi

CC BY SA 2021 


\section{Pendahuluan}

Transportasi dan komunikasi merupakan salah satu faktor yang sangat mempengaruhi pendapatan suatu daerah maupun Negara (Szkudlarek et al., 2020). Hal ini dikarenakan perkembangan media transportasi dan komunikasi sangat maju dan menjanjikan terkhusus di zaman modern seperti sekarang ini (Abugre, 2018). Hal ini membuat bidang tersebut menjadi salah satu penyumbang paling tinggi terhadap PDB nasional di negara Indonesia. Maka dari itu ketika penyediaan transportasi meningkat maka GDP atau gross domestic product nasional juga akan meningkat (Nugrahani \& Yudhistira, 2021).

DKI Jakarta merupakan ibukota Indonesia yang memiliki peran penting sebagai pusat pemerintahan dan juga pusat bisnis di Indonesia. Selain itu DKI Jakarta juga memiliki banyak sekali tempat wisata yang akan menjadi daya tarik bagi masyarakat untuk berwisata di kota ini. Dengan demikian, mobilitas transportasi dan perpindahan di kota ini sangat meningkat baik perpindahan penumpang maupun barang serta dapat mempengaruhi pertumbuhan ekonomi dan pendapatan daerah (Estiningsih \& Nurranto, 2020).

Pada tahun 2019 sektor transportasi menyumbang sebesar 3,44\% kepada PDRB daerah ibukota Jakarta. PDRB Sektor Transportasi ini mencakup beberapa faktor yaitu: angkutan rel, angkutan darat, angkutan laut, angkutan penyebrangan, angkutan udara, serta angkutan jasa seperti pos dan kurir. Angkutan darat menjadi penyumbang terbesar di bidang transportasi dengan nilai 41,6\% dari total keseluruhan PDRB di sektor transportasi (MPOC, 2020).

Berdasarkan fakta-fakta yang tertera diatas maka kami akan menganalisa bagaimana pengaruh sektor transportasi dan komunikasi terhadap PDB nasional Indonesia serta apakah hal tersebut juga berpengaruh terhadap PDRB kota DKI Jakarta yang merupakan salah satu daerah dengan mobilitas perpindahan yang cukup tinggi. Selain itu kami juga akan menganalisa bagaimana sektor transportasi dapat menjadi salah satu sektor paling berpengaruh dalam PDRB daerah (Umar et al., 2020).

Tujuan Penelitian ini adalah: 1) Untuk mengetahui sektor apa yang paling berpengaruh dan menjadi penyumbang terbesar di dalam PDRB kota DKI Jakarta. 2) Untuk mengetahui bagaimana peran sektor transportasi dan komunikasi di dalam PDRB DKI Jakarta. 3) Untuk mengetahui seberapa besar pengaruh sektor transportasi dan komunikasi dalam bentu presentase terhadap PDRB DKI Jakarta. 4) Mengetahui sektor apa saja yang berperan penting di dalam PDRB DKI Jakarta. 5) Mengetahui faktor-faktor apa saja yang dapat menjadi faktor pendukung untuk meningkatkan pendapatan daerah khususnya DKI Jakarta.

\section{Metode Penelitian}

Metode penelitian merupakan cara atau jalur yang dilalui peneliti untuk mendapatkan dan melakukan penelitian mereka. Metode ini menunjukkan arah di mana para peneliti ini merumuskan suatu masalah atau tujuan mereka dan mendeskripsikan hasil mereka dari data yang diperoleh selama masa penelitian. Berikut ini kami akan menyajikan berupa jenis penelitian, teknik pengumpulan data, serta pupulasi dan sampel penelitian (Ørngreen \& Levinsen, 2017).

Jenis metode penelitian yang kami proses berupa analisis data kualitatif, metode ini merupakan metode yang kami kumpulkan untuk memproses dan mengurutkan data yang telah kami dapatkan supaya sesuai dengan topik yang dibahas. metode kualitatif cenderung lebih menonjolkan pada aspek-aspek pemahaman lebih dalam terhadap suatu masalah. Kemudian 
data yang dikumpulkan akan dibuat pembahasan lebih mendalam sesuai dengan data yang telah dipersiapkan secara logis dan sistematis.

Mengenai sumber data, kami memperoleh data dengan data sekunder. Jenis data yang kami gunakan yaitu data sekunder yang bersifat kualitatif. Metode Data sekunder adalah data yang di dapat melalui sumber yang telah ada atau di dapat secara tidak langsung biasanya melalui media perantara, seperti buku, website, jurnal, ebook dan catatan histori yang terpercaya dan aktual. kami memanfaatkan data sekunder dalam penelitian ini di karenakan data didapatkan melalui sumber yang tidak langsung ataupun sumber perantara. Sumber yang kami gunakan yaitu berupa jurnal international. Tujuan kami mengunakan data sekunder ialah karena lebih akurat, lebih mudah dan cepat untuk memperoleh data penelitian, sehingga kami bisa mengumpulkan data atau informasi dari sumber-sumber terpercaya agar lebih akurat dan istematis.

Selama pengumpulan data, kami mengumpulkan data dengan menggunakan teknik dokumentasi. Teknik ini merupakan pengumpulan beberapa sumber data yang berhubungan dengan variabel penelitian. Selain itu, cara lain kami mengumpulkan teknik pengumpulan data lainnya yaitu dengan memperoleh data melalui Badan Pusat Statistik DKI Jakarta pada periode yang telah diperbaharui, dan kami juga memperoleh beberapa data dari artikel yang berhubungan dengan pembahasan ini.

Populasi dan sampel dalam penelitian ini memeiliki perbedaan utama yang berkaitan dengan bagaimana suatu observasi ditetapkan dalam pengumpulan data. Pupulasi mencakup semua elemen dari sekumpulan data, sedangkan sampel terdiri dari satu atau lebih observasi yang diambil dari populasi (Pereira et al., 2017).

Terdapat dua sektor populasi pada penelitian ini yang termasuk didalam Produk Domestic Regional Bruto (PDRB). Adapun dua sektor yang kami pilih untuk penelitia ini yaitu sektor transportasi dan komunikasi. Pemilihan sampel penelitian yaitu berdasarkan dengan metode purposive sampling, yang merupakan pemilihan sampel berdasarkan dari berbagai penelitian tertentu.

\section{Hasil dan Pembahasan}

DKI Jakarta merupakan ibukota negara Indonesia dengan jumlah penduduk yang sangat banyak. Hal ini dikarenakan DKI Jakarta memiliki banyak sekali lapangan pekerjaan sehingga membuat banyak masyarakat yang melakukan perpindahan ke provinsi ini. Maka dari itu tingkat mobilitas di DKI Jakarta juga sangat tinggi baik dari jalur darat, air maupun udara. Kegiatan transportasi di provinsi setiap harinya sangat padat dan itu menjadi alasan sektor transportasi merupakan salah satu penyumbang terbesar ddi PDRB Provinsi DKI Jakarta. Melalui data yang sudah kami dapatkan berikut jumlah penduduk yang ada di provinsi DKI Jakarta sebagai berikut:

\section{Tabel 1}

Jumlah Penduduk di Provinsi Jakarta

\begin{tabular}{lc}
\hline \multicolumn{1}{c}{ Kabupaten/Kota } & Kepadatan Penduduk per km \\
\hline Kepulauan Seribu & $2.714,48$ \\
Jakarta Selatan & $15.620,67$ \\
Jakarta Timur & $15.257,72$ \\
\hline
\end{tabular}




\begin{tabular}{cc}
\hline Jakarta Pusat & $19.068,23$ \\
Jakarta Barat & $19.268,20$ \\
Jakarta Utara & $12.032,01$ \\
\hline DKI Jakarta & $\mathbf{1 5 . 5 1 7 , 3 8}$ \\
\hline
\end{tabular}

\section{Sumber: DPMPTSP DKI Jakarta}

Berdasarkan data diatas dapat kita ketahui bahwa jakarta menjadi provinsi dengan tingkat kepadatan penduduk yang sangat tinggi. Hal ini sudah pasti berpengaruh terhadap mobilitas dan transportasi daerah. Sudah banyak peningkatan yang dilakukan dalam sektor transportasi seperti pembangunan MRT, perbaikan stasiun, pembangunan transjakarta dan lain sebagainya. Maka dari itu kita akan membahas pendapatan serta operasional dari masing-masing jenis transportasi di DKI Jakarta sebagai berikut:

\section{- TRANSJAKARTA}

Bus Transjakarta umumnya disebut Busway yang merupakan sebuah sistem transportasi Bus Rapid Transit (BRT) pertama di Asia Tenggara dan Selatan dan bus transjakarta sudah mulai beroperasi sejak tahun 2004 di DKI Jakarta. Bus jenis ini dioperasikan oleh PT. Transportasi Jakarta (TransJakarta). Berikut pendapatan dari bus transjakarta:

\section{Gambar 1. Pendapatan Bus Transjakarta}

\begin{tabular}{|c|c|c|c|}
\hline Konidor & Rute & $\begin{array}{l}\text { Penumpang } \\
\text { (Juta Orang) }\end{array}$ & $\begin{array}{l}\text { Pendapatan } \\
\text { (Rp. Malliar) }\end{array}$ \\
\hline Koridor 1 & Blok M - Kota & 23,98 & 80,89 \\
\hline Koridor II & Pulo Gadung - Harmoni & 7.35 & 23,83 \\
\hline Koridor III & Harmoni - Kalideres & 9,48 & 30,32 \\
\hline Koridor IV & Pulo Gadung - Dukuh Atas & 6,58 & 21,28 \\
\hline Koridor V & Kampung Melayu - Ancol & 9,84 & 32,46 \\
\hline Koridor VI & Ragunan - Kuningan & 10,01 & 32,64 \\
\hline Koridor VII & Kp. Melayu - Kp. Rambutan & 8.82 & 27,73 \\
\hline Koridor VIII & Lebak Bulus - Harmoni & 10,09 & 33,32 \\
\hline Koridor IX & Pinang Ranti - Pluit & 14,37 & 46,91 \\
\hline Koridor X & Cilititan - Tanjung Priok & 6.57 & 21,28 \\
\hline Koridor XI & Kp. Melayu - Pulo Gebang & 2,76 & 8,61 \\
\hline Koridor XII & Pluit - Tanjung Priok & 1.89 & 6,15 \\
\hline Lainnya & - & 11,98 & 31,64 \\
\hline \multicolumn{2}{|r|}{ Total } & 123,71 & 397,04 \\
\hline
\end{tabular}

- Kereta Api

Angkutan berbasis rel di DKI Jakarta terdiri dari angkutan regular antar wilayah di Pulau Jawa yang dikelola PT. KAI Daops I Jakarta dan Commuterline yang dikelola oleh PT. KAI Commuter Jabodetabek (berganti nama PT. Kereta Commuter Indonesia / PT. KCI). Dengan menjadikan "Best Choice for Urban Transport" KCI saat ini terus berbenah untuk memenuhi target melayani 1,2 juta penumpang per hari dengan kekuatan armada KRL hingga 1.450 unit pada tahun 2019. Hingga akhir 2016, KCJ mengoperasikan 18 kereta yang memiliki rangkaian 12 kereta, dan 29 kereta yang memiliki rangkaian 10 kereta. Rata-rata penumpang harian commuter line mencapai 833,67 ribu orang di 
sepanjang tahun lalu. Puncak volume tertinggi terjadi pada 2 Juni 2016 sebanyak 931,08 ribu orang. Dibawah ini adalah jumlah penumpang serta barang yang diangkut oleh kereta api:

\section{Gambar 2. Jumlah Penumpang dan Barang yang di angkut}

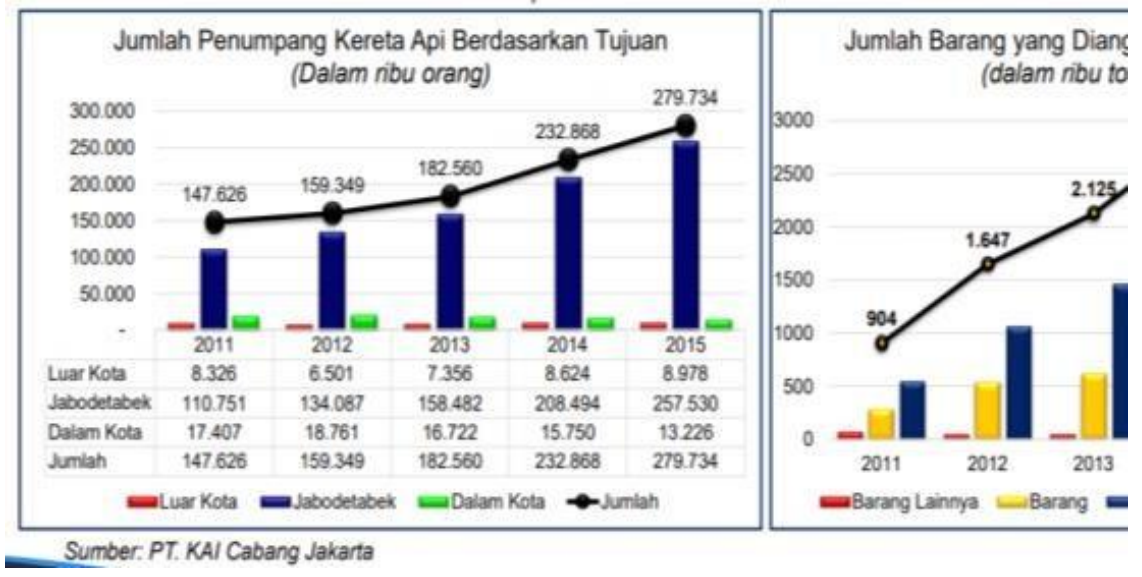

Dengan data- data yang sudah tertera diatas maka kita bisa mengambil kesimpulan bahwa sektor transportasi memberikan pengaruh yang cukup besar terhadap PDRB kota DKI Jakarta. Dikarenakan perpindahan serta mobilitas di kota ini sangat tinggi. Pada tahun 2019 sektor transportasi menyumbang sebesar 3,44\% kepada PDRB daerah ibukota Jakarta. PDRB Sektor Transportasi ini mencakup beberapa faktor yaitu: angkutan rel, angkutan darat, angkutan laut, angkutan penyebrangan, angkutan udara, serta angkutan jasa seperti pos dan kurir. Angkutan daratmenjadi penyumbang terbesar di bidang transportasi dengan nilai 41,6\% dari total keseluruhan PDRB di sektor transportasi.

Berdasarkan fakta diatas maka dapat kita simpulkan bahwa sektor transportasi memiliki pengaruh besar terhadap PDRB DKI Jakarta sehingga sektor ini harus mendapatkan perhatian lebih dari pemerintah agar sektor ini dapat terus meningkatkan kualitas dan pelayanan yang juga akan berdampak terhadap pendapat daerah terkhusus di provinsi DKI Jakarta. Dengan inovasi inovasi terbaru maka sektor ini cukup menjanjikan untuk kemajuan di masa depan karena transportasi akan selalu menjadi bagian yang penting di suatu daerah baik secara nasional maupun internasional.

\section{Kesimpulan}

Berdasarkan hasil analisis penulis, pengaruh sektor transportasi dan komunikasi signifikan terhadap pendapatan daerah DKI Jakarta. Pada tahun 2019 sektor transportasi tersebut menyumbang sebesar 3,44\% terhadap pendapatan daerah tersebut. Maka dari itu sektor transportasi ini perlu di tingkatkan untuk kedepannya supaya bisa membantu pertumbuhan daerah yang lebih baik.

Rekomendasi yang bisa penulis kasih untuk masyarakat dan pemerintah agar bisa bekerja sama dengan baik dalam meningkatkan pendapatan daerah melalui tranportasi dan komunikasi. 


\section{Bibliografi}

Abugre, J. B. (2018). Cross-cultural communication imperatives. Critical Perspectives on International Business.

Estiningsih, W., \& Nurranto, H. (2020). Analisis Efektivitas Pajak Parkir dalam Meningkatkan Pendapatan Asli Daerah di Wilayah Jakarta Selatan. Sosio E-Kons, 12(02), 172-183.

MPOC. (2020). No 主観的健康感を中心とした在宅高齢者における 健康関連指標に関 する共分散構造分析Title.”. Malaysian Palm Oil Council (MPOC), 21((1)), 1-9.

Nugrahani, S., \& Yudhistira, M. H. (2021). Apakah Keberadaan Mass Rapid Transit Berdampak terhadap Transjakarta? Studi Kasus Transportasi Publik di DKI Jakarta. Jurnal Ekonomi \& Kebijakan Publik, 11(2), 133-147.

Ørngreen, R., \& Levinsen, K. (2017). Workshops as a Research Methodology. Electronic Journal of E-Learning, 15(1), 70-81.

Pereira, P., Seghatchian, J., Caldeira, B., Santos, P., Castro, R., Fernandes, T., Xavier, S., de Sousa, G., \& e Sousa, J. P. de A. (2017). Sampling methods to the statistical control of the production of blood components. Transfusion and Apheresis Science, 56(6), 914919.

Szkudlarek, B., Osland, J. S., Nardon, L., \& Zander, L. (2020). Communication and culture in international business-Moving the field forward. Journal of World Business, 55(6), 101126.

Umar, M., Ji, X., Kirikkaleli, D., \& Xu, Q. (2020). COP21 Roadmap: Do innovation, financial development, and transportation infrastructure matter for environmental sustainability in China? Journal of Environmental Management, 271, 111026. 